Article

\title{
Entropy Generation Analysis and Performance Evaluation of Turbulent Forced Convective Heat Transfer to Nanofluids
}

\author{
Yu Ji ${ }^{1}$, Hao-Chun Zhang ${ }^{2, *}$, Xie Yang ${ }^{1}$ and Lei Shi ${ }^{1, *}$ \\ 1 Institute of Nuclear and New Energy Technology, Collaborative Innovation Center of Advanced Nuclear \\ Energy Technology, Key Laboratory of Advanced Reactor Engineering and Safety of Ministry of Education, \\ Tsinghua University, Beijing 100084, China; jiyu1994joe11@163.com (Y.J.); yxheneng@163.com (X.Y.) \\ 2 School of Energy Science and Engineering, Harbin Institute of Technology, Harbin 150001, China \\ * Correspondence: zhc5@vip.163.com (H.-C.Z.); shlinet@tsinghua.edu.cn (L.S.); \\ Tel.: +86-451-8641-2328 (H.-C.Z.); +86-10-6277-3361 (L.S.)
}

Academic Editor: Yan Jin

Received: 21 January 2017; Accepted: 8 March 2017; Published: 11 March 2017

\begin{abstract}
The entropy generation analysis of fully turbulent convective heat transfer to nanofluids in a circular tube is investigated numerically using the Reynolds Averaged Navier-Stokes (RANS) model. The nanofluids with particle concentration of $0 \%, 1 \%, 2 \%, 4 \%$ and $6 \%$ are treated as single phases of effective properties. The uniform heat flux is enforced at the tube wall. To confirm the validity of the numerical approach, the results have been compared with empirical correlations and analytical formula. The self-similarity profiles of local entropy generation are also studied, in which the peak values of entropy generation by direct dissipation, turbulent dissipation, mean temperature gradients and fluctuating temperature gradients for different Reynolds number as well as different particle concentration are observed. In addition, the effects of Reynolds number, volume fraction of nanoparticles and heat flux on total entropy generation and Bejan number are discussed. In the results, the intersection points of total entropy generation for water and four nanofluids are observed, when the entropy generation decrease before the intersection and increase after the intersection as the particle concentration increases. Finally, by definition of $E_{\mathrm{p}}$, which combines the first law and second law of thermodynamics and attributed to evaluate the real performance of heat transfer processes, the optimal Reynolds number $R e_{\mathrm{op}}$ corresponding to the best performance and the advisable Reynolds number $R e_{\text {ad }}$ providing the appropriate Reynolds number range for nanofluids in convective heat transfer can be determined.
\end{abstract}

Keywords: nanofluids; turbulent flow; convective heat transfer; entropy generation; performance evaluation

\section{Introduction}

Facilities with high power density account for an increasing share in some industries as the technology advances, which demands an effective approach to ensure safe and efficient heat transfer. For the last several decades, many methods have been utilized to enhance heat transfer, such as changing flow geometry or boundary conditions and improving the properties of working fluids. Nanofluids technique is an approach for increasing the nominal fluid thermal conductivity through suspending nanometer-sized particles in a base fluid [1]. Usually, the particles are metals, metal-oxides such as $\mathrm{Cu}, \mathrm{Au}, \mathrm{CuO}, \mathrm{TiO}_{2}, \mathrm{Al}_{2} \mathrm{O}_{3}$, or even carbon nanotubes, while the base fluid is a poor heat transfer fluid, including oil, water and ethylene glycol [2]. In terms of their unique features, nanofluids have attracted a great deal of attention and several experimental and numerical investigations have been conducted to analyze their thermal and hydrodynamics characteristics. For example, He et al. [3] 
investigated the laminar and turbulent convective heat transfer to $\mathrm{TiO}_{2}$ nanofluids, and found that heat transfer rate is better when the particle concentration increases and particle size decreases. Xuan and $\mathrm{Li}[4,5]$ investigated the heat transfer coefficient and friction factor of $\mathrm{Cu}$-water nanofluids experimentally, and the results showed that heat transfer capability enhanced significantly as particle loading rises. Additionally, Xuan et al. [6] correlated a formula evaluating heat transfer to capture the effect of energy transport due to particle dispersion. Rea et al. [7] explored the difference of laminar convective heat transfer to $\mathrm{Al}_{2} \mathrm{O}_{3}$-water and $\mathrm{ZrO}$-water nanofluids in a vertical heated tube. An increment of $17 \%$ in heat transfer coefficient in the entrance region and $27 \%$ in developed region for $6 \mathrm{vol} \% \mathrm{Al}_{2} \mathrm{O}_{3}$-water nanofluids was observed, while it was reduced to $2 \%$ in the entry length and $3 \%$ in the developed region for $1.32 \mathrm{vol} \% \mathrm{ZrO}$-water nanofluids. Maige et al. [8] studied the thermal and hydrodynamic characteristic of two nanofluids, viz., water- $\gamma \mathrm{Al}_{2} \mathrm{O}_{3}$ and ethylene glycol- $\gamma \mathrm{Al}_{2} \mathrm{O}_{3}$ in a uniformly heated tube, which show that the heat transfer rate using ethylene glycol- $\gamma \mathrm{Al}_{2} \mathrm{O}_{3}$ is much better than that using water- $\gamma \mathrm{Al}_{2} \mathrm{O}_{3}$ mixture. Bianco et al. [9] investigated the flow and heat transfer behavior of water- $\mathrm{Al}_{2} \mathrm{O}_{3}$ nanofluid in a circular tube numerically, in which they adopted the mixture model and compared the results with the single-phase model, which regarded the nanofluids as single phase fluid of effective properties and was used frequently in amounts of researches [10-14]. The similar results derived by single phase model and mixture model indicated that heat transfer was augmented with the increase of volume fraction of particles and Reynolds number.

Besides the work stated above, the mechanisms of thermal transport in nanofluids involving Brownian motion, interfacial resistance, liquid layering at particle liquid interface, motion of nanoparticles clustering and thermophoresis have also been investigated in some explorations [15-19]. Both the experimental and numerical studies revealed the absolute potential of nanofluids in heat transfer enhancement.

However, most studies on nanofluids just focused on the heat transfer coefficient and pressure drop under the framework of first law of thermodynamics. Evidently, the enhancement of heat transfer performance is accompanied by the increase of pressure drop penalty, which results from that the improvement of thermal conductivity is accompanied by the increase of viscosity [20]. Although much information about heat transfer to nanofluids can be obtained through first law analysis, little is known about the exergy and dissipation. Moreover, the optimal condition cannot be determined by first law approach in a viewpoint of energy utilization. Entropy generation analysis is an effective method to determine the irreversibility of energy processes or thermal engineering systems. Entropy generation minimization method (EGM) introduced by Bejan [21] is a combination of fluid mechanics, heat transfer and thermodynamics. Nowadays, it is widely used in many applications including the friction and heat transfer assessment of fluid flow and heat transfer [22-24], drag reduction of channels with shark skin surfaces [25], performance improvement of two-phase natural circulation loops [26], optimization of heat pipe systems and refrigeration systems $[27,28]$. Beyond question, EGM has been applied to the analysis of nanofluids problems successfully.

Singh et al. [29] conducted an analytical study of laminar nanofluids flow in three scale geometries, i.e., microchannels, minichannels and conventional channels. Li et al. [13] investigated the entropy generation of $\mathrm{Al}_{2} \mathrm{O}_{3}$-water nanofluids laminar flow in the microchannels with flow control structures. Recently, more attention has been paid to the turbulent flow regime of nanofluids. Bianco et al. [30] carried out a parametric investigation of entropy generation of turbulent forced convective heat transfer to $\mathrm{Al}_{2} \mathrm{O}_{3}$-water nanofluids in a circular tube subjected to constant wall heat flux. The results determined the optimal particle concentration to minimize entropy generation for different inlet conditions and a concentration range from $0 \%$ up to $6 \%$. Mwesigye and Huan [20] performed a thermodynamics analysis and optimization of fully developed turbulent convective heat transfer to water- $\mathrm{Al}_{2} \mathrm{O}_{3}$ nanofluids in a tube with circular section, in which the effects of cross section areas, particle concentration and Reynolds number on entropy generation were discussed. Siavashi and Jamali [31] analyzed the entropy generation of $\mathrm{TiO}_{2}$-water nanofluids flowing through annuli with different radius ratios and the optimal working condition was found to reach the minimum irreversibility. 
From the literature review above, it can be noticed that almost all work related to the entropy generation of nanofluids emphasized the general parameters, but no detailed information, such as entropy generation profile in the flow field of nanofluids was not provided, which prevents us from better understanding the mechanism and optimizing these sophisticated devices. Therefore, in the current work, the fully developed turbulent flow of $\mathrm{Al}_{2} \mathrm{O}_{3}$-water nanofluids is investigated numerically. The entropy generation distribution within fluid domain is determined first, and then a parametric study of thermodynamic irreversibility is performed. Finally, the evaluation parameter $E_{\mathrm{p}}$, which is a combination criterion of the first law and second law of the thermodynamics, is introduced to evaluate the performance of convective heat transfer processes, and the effects of Reynolds number, heat flux, and particle concentration on it are discussed as well.

\section{Problem Description}

The geometry model of the problem being investigated in this paper is depicted in Figure 1. It is a circular tube with the uniform heat flux at the wall. The length of the tube is $1 \mathrm{~m}$ and the diameter is $1 \mathrm{~cm}$.

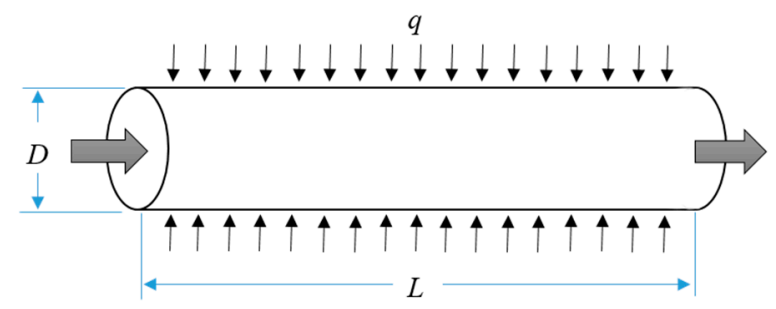

Figure 1. Schematic view of circular tube being investigated in this paper.

The turbulent flow at different Reynolds number is taken into account. The nanofluids whose particle concentration ranges from $0 \%$ to $6 \%$ consist of water and $\mathrm{Al}_{2} \mathrm{O}_{3}$ nanoparticle of $25 \mathrm{~nm}$ sphere, and the Reynolds number is determined by bulk velocity, tube diameter and effective properties of nanofluids. In the investigation, the nanofluids are treated as single phase fluids with constant properties, which will be introduced in the following part of this paper.

\section{Numerical Approach}

\subsection{Properties of Nanofluids}

Correct specification of thermodynamic and transport properties is significant in the simulation of convective heat transfer to nanofluids, which determines the accuracy of the analysis usually. In this investigation, the sole properties of $\mathrm{Al}_{2} \mathrm{O}_{3}$ nanoparticle and the water base fluid are listed in Table 1 , and the determination of mixtures is introduced as below.

Table 1. Properties of base fluid and $\mathrm{Al}_{2} \mathrm{O}_{3}$ nanofluids [32].

\begin{tabular}{ccccc}
\hline Substances & $\rho\left(\mathbf{k g} / \mathbf{m}^{3}\right)$ & $c_{\boldsymbol{p}}(\mathrm{J} / \mathbf{k g} \cdot \mathrm{K})$ & $\mu(\mathbf{P a} \cdot \mathbf{s})$ & $\lambda(\mathbf{W} / \mathbf{m} \cdot \mathrm{K})$ \\
\hline Water & 998.2 & 4182.0 & 0.001003 & 0.6 \\
$\mathrm{Al}_{2} \mathrm{O}_{3}$ & 3970 & 765 & - & 40 \\
\hline
\end{tabular}

Density of the $\mathrm{Al}_{2} \mathrm{O}_{3}$-water mixture is given by [8]:

$$
\rho_{n f}=\phi \rho_{p}+(1-\phi) \rho_{b f} .
$$

By assuming the thermal equilibrium between the base fluid and particle, the specific heat capacity is calculated as follows [20]: 


$$
c_{p, n f}=\frac{\phi \rho_{p} c_{p, p}+(1-\phi) \rho_{b f} c_{p, b f}}{\rho_{n f}} .
$$

As for viscosity, the empirical correlation proposed by Maiga et al. [8] is adopted, which reads as:

$$
\mu_{n f}=\mu_{b f}\left(123 \phi^{2}+7 \cdot 3 \phi+1\right) .
$$

The correlation has been used in several studies [8,14,33-38]. It is obtained by a least squares curve fitting of experimental data from Wang et al. [39]. On one hand, the correlation gives the viscosity value close to the experimental values when compared with earlier models proposed by Einstein and later modified by Brinkman [40] as well as one also proposed by Batchelor [41]. On the other hand, the expression of correlation is simpler than some recent models [42]. Besides, the correlation can give the viscosity for water- $\mathrm{Al}_{2} \mathrm{O}_{3}$ nanofluids with particle concentration up to $6 \%$.

Thermal conductivity is determined by Bruggeman model [43], which takes the interaction among spherical particles into consideration, and is written as:

$$
\begin{aligned}
& \lambda_{n f}=\left[(3 \phi-1) \lambda_{p}+(2-3 \phi) \lambda_{b f}+\sqrt{\Delta}\right] / 4, \\
& \Delta=\left[(3 \phi-1) \lambda_{p}+(2-3 \phi) \lambda_{b f}\right]^{2}+8 \lambda_{p} \lambda_{b f} .
\end{aligned}
$$

The model is popular in some investigations due to its simplicity $[13,20,36,44]$. From the results of some studies, the Bruggeman model approaches the Maxwell model at low nanoparticle concentration, which gives the thermal conductivity of nanofluids accurately in a benchmark test carried out by 34 organizations [45]. The Maxwell model and its improved versions have been adopted to determine the thermal conductivity of nanofluids successfully in the last several decades [13,20,44,45]. In addition, the Bruggeman model is more appropriate to use for high quantities of particle loading when compared with Maxwell model [46,47].

In the statement above, the subscript $n f$ represents nanofluid, $b f$ represents base fluid and $p$ means particles.

\subsection{Governing Equations of CFD Calculation}

The turbulent convective heat transfer is investigated by means of solving the incompressible steady Navier-Stokes equation numerically here, and the governing equations after averaging are listed below, in which the subscript " $n f$ " is omitted to ensure the conciseness of equations:

- Continuity equation:

$$
\frac{\partial\left(\rho \bar{u}_{i}\right)}{\partial x_{i}}=0,
$$

- Momentum equation:

$$
\frac{\partial}{\partial x_{j}}\left(\rho \bar{u}_{i} \bar{u}_{j}\right)=-\frac{\partial P}{\partial x_{i}}+\frac{\partial}{\partial x_{j}}\left(\left(\mu+\mu_{t}\right)\left(\frac{\partial \bar{u}_{i}}{\partial x_{j}}+\frac{\partial \bar{u}_{j}}{\partial x_{i}}\right)\right),
$$

- Energy equation:

$$
\frac{\partial}{\partial x_{j}}\left(\rho \bar{u}_{j} c_{p} \bar{T}\right)=\frac{\partial}{\partial x_{j}}\left(\left(\lambda+\alpha_{t} \rho c_{p}\right) \frac{\partial \bar{T}}{\partial x_{j}}\right)+\mu\left(\frac{\partial \bar{u}_{i}}{\partial x_{j}}+\frac{\partial \bar{u}_{j}}{\partial x_{i}}\right) \frac{\partial \bar{u}_{i}}{\partial x_{j}},
$$

where the variables with bar represent mean parameters, i.e., mean velocity and mean temperature. The $\mu_{t}$ and $\alpha_{t}$ are the turbulent viscosity and turbulent thermal diffusivity separately, which should be determined using the turbulence model, i.e., standard $k-\omega$ model in this work. The model has 
incorporated modifications for low-Reynolds number effects and shear flow spreading. The transport equations of turbulence kinetic energy $k$ and the specific dissipation rate $\omega$ yield as [48]:

$$
\begin{gathered}
\frac{\partial}{\partial x_{j}}\left(\rho k \bar{u}_{j}\right)=\frac{\partial}{\partial x_{j}}\left(\Gamma_{k} \frac{\partial k}{\partial x_{j}}\right)+G_{k}-Y_{k}, \\
\frac{\partial}{\partial x_{j}}\left(\rho \omega \bar{u}_{j}\right)=\frac{\partial}{\partial x_{j}}\left(\Gamma_{\omega} \frac{\partial \omega}{\partial x_{j}}\right)+G_{\omega}-Y_{\omega},
\end{gathered}
$$

in which, $G_{k}$ represents the production term of turbulence kinetic energy due to mean velocity gradients, while $Y_{k}$ represents the dissipation term of turbulence kinetic energy due to turbulence, analogously in the equation of specific dissipation rate $\omega$. Besides, $\Gamma_{k}$ and $\Gamma_{\omega}$ are the diffusivity of $k$ and $\omega$ respectively. The detailed introduction of these term can be obtained in [48]. Through the values of $k$ and $\omega$, the turbulent viscosity and thermal diffusivity are computed as:

$$
\begin{aligned}
& \mu_{t}=\alpha^{*} \frac{\rho k}{\omega}, \\
& \alpha_{t}=\frac{\mu_{t}}{\rho P r_{t}},
\end{aligned}
$$

where $P r_{t}$ is the turbulent Prandtl number and the coefficient $\alpha^{*}$ is a damping function of turbulent viscosity accounting for low-Reynolds number correction, and it is given by [48]:

$$
\alpha^{*}=\alpha_{\infty}^{*}\left(\frac{\alpha_{0}^{*}+R e_{t} / R_{k}}{1+R e_{t} / R_{k}}\right),
$$

in which, $\alpha^{*}=\alpha_{\infty}^{*}=1$ for high-Reynolds number flow, and the variables or parameters are calculated as [48]:

$$
\begin{gathered}
R e_{t}=\frac{\rho k}{\mu \omega}, \\
R_{k}=6, \alpha_{0}^{*}=\frac{\beta_{i}}{3}, \beta_{i}=0.072 .
\end{gathered}
$$

\subsection{Entropy Generation}

The irreversibility of convective heat transfer consists of two part, viz., flow friction due to viscous and heat transfer with finite temperature difference. For turbulent flows, the entropy generation describing the irreversibility can be divided into four terms:

$$
\begin{aligned}
& \dot{S}_{\text {gen }, \overline{\mathrm{D}}}^{\prime \prime \prime}=\frac{\mu}{\bar{T}}\left\{2\left(\frac{\partial \bar{u}_{i}}{\partial x_{i}}\right)^{2}+\left(\frac{\partial \bar{u}_{i}}{\partial x_{j}}+\frac{\partial \bar{u}_{j}}{\partial x_{i}}\right)^{2}\right\}, \\
& \dot{S}_{\text {gen, } \mathrm{D}^{\prime}}^{\prime \prime \prime}=\frac{\mu}{\bar{T}}\left\{2 \overline{\left(\frac{\partial u_{i}^{\prime}}{\partial x_{i}}\right)^{2}}+\overline{\left(\frac{\partial u_{i}^{\prime}}{\partial x_{j}}+\frac{\partial u_{j}^{\prime}}{\partial x_{i}}\right)^{2}}\right\} \text {, } \\
& \dot{S}_{\text {gen, } \overline{\mathrm{C}}}^{\prime \prime \prime}=\frac{\lambda}{\bar{T}^{2}}\left(\frac{\partial \bar{T}}{\partial x_{i}}\right)^{2}, \\
& \dot{S}_{\text {gen, } C^{\prime \prime \prime}}^{\prime \prime}=\frac{\lambda}{\bar{T}^{2}} \overline{\left(\frac{\partial T^{\prime}}{\partial x_{i}}\right)^{2}},
\end{aligned}
$$

which represent entropy generation by direct dissipation, entropy generation by turbulent dissipation, entropy generation by heat conduction for mean temperature gradients, and entropy generation by heat transfer for fluctuating temperature gradients according to [49]. However, Equations (17) and (19) 
involve the velocity and temperature fluctuations, which cannot be obtained from RANS approach. Then the information contained in the turbulence model, standard $k-\omega$ model should be applied to update these two terms in a close form, which are shown as [22,49]:

1. By assuming the local equilibrium of turbulent kinetic energy, the exact dissipation approximately equals to the production of density and the turbulent dissipation rate; the turbulent dissipation rate is directly proportional to the production of turbulence kinetic energy and specific turbulent dissipation rate; therefore, the equation can be rewritten as:

$$
\dot{S}_{\text {gen, }}^{\prime \prime \prime}=\frac{\rho \varepsilon}{\bar{T}}=C_{\mu} \frac{\rho k \omega}{\bar{T}},
$$

in which, the coefficient $C_{\mu}$ is set as a constant, 0.09 .

2. By using the Boussinesq approach and a constant turbulent Prandtl number, the entropy generation because of fluctuating temperature gradients is replaced by:

$$
\dot{S}_{\text {gen, } C^{\prime \prime \prime}}^{\prime \prime}=\alpha_{t} \frac{\rho c_{p}}{\bar{T}^{2}}\left(\frac{\partial \bar{T}}{\partial x_{i}}\right)^{2}=\frac{\mu_{t}}{P r_{t}} \frac{c_{p}}{\bar{T}^{2}}\left(\frac{\partial \bar{T}}{\partial x_{i}}\right)^{2}=\frac{\alpha^{*} k}{\omega P r_{t}} \frac{\rho c_{p}}{\bar{T}^{2}}\left(\frac{\partial \bar{T}}{\partial x_{i}}\right)^{2} .
$$

Summarizing the four terms above, the total volumetric entropy generation rate is given as:

$$
\dot{S}_{\text {gen }}^{\prime \prime \prime}=\dot{S}_{\text {gen, } \overline{\mathrm{D}}}^{\prime \prime \prime}+\dot{S}_{\text {gen, } \mathrm{D}^{\prime}}^{\prime \prime \prime}+\dot{S}_{\text {gen, } \overline{\mathrm{C}}}^{\prime \prime \prime}+\dot{S}_{\text {gen, } \mathrm{C}^{\prime}}^{\prime \prime \prime}
$$

Integrating volumetric entropy generation rate to the whole computational domain, the total entropy generation rate is determined as:

$$
\dot{S}_{\text {gen }}=\int_{V} \dot{S}_{\text {gen }}^{\prime \prime \prime} \mathrm{d} V
$$

\subsection{Boundary Conditions}

To get fully developed turbulent flow inside the tube, the periodic boundary conditions are adopted at the inlet and outlet section. The mass flow rate corresponding to different Reynolds number and particle concentration of nanofluids are specified here. Besides, the inlet temperature is set as $293 \mathrm{~K}$. For the tube wall, the uniform heat flux boundary with no slip and no penetration is selected. To investigate the effect of heat flux on the entropy generation, the heat flux with the values of $50,000 \mathrm{~W} / \mathrm{m}^{2}, 100,000 \mathrm{~W} / \mathrm{m}^{2}, 200,000 \mathrm{~W} / \mathrm{m}^{2}$ and $500,000 \mathrm{~W} / \mathrm{m}^{2}$ is considered in this study.

\subsection{Solution Method}

The solution of the problem is performed using ANSYS FLUENT 16.0, a computational fluid dynamics code based on finite volume method. In the simulation, the Semi-Implicit Method for Pressure-Linked Equations-Consistent (SIMPLEC) algorithm is adopted for pressure-velocity coupling, and the second upwind scheme is used for spatial discretization of equations with regards to continuity, momentum, energy, turbulent kinetic energy and specific dissipation. During the simulation, the calculation will not be terminated unless the two criteria below are attained [22]: (1) The scaled residuals for all solutions except energy should be less than $10^{-6}$, while the term for energy is set to $10^{-9}$; (2) The entropy generation rate integrated to whole domain hardly changes with iterations.

\section{Results and Discussion}

\subsection{Verification and Validation}

In the verification process, four meshes are chosen to check the grid independence under the condition of convective heat transfer using pure water at $R e=40,000$. The friction factor $f$, Nusselt number $\mathrm{Nu}$ and dimensionless total entropy generation $N_{s}$ are selected as evaluation criteria. The simulation results are shown in Table 2. 
Table 2. Results of grid independence check.

\begin{tabular}{cccccccc}
\hline & Nodes & $f$ & Difference (\%) & $\boldsymbol{N u}$ & Difference (\%) & $\boldsymbol{N}_{\boldsymbol{s}}{ }^{*}$ & Difference (\%) \\
\hline 1 & 157,628 & 0.0249 & 8.52 & 306.2722 & 5.65 & 0.01756 & 16.8 \\
2 & 268,068 & 0.0229 & 3.00 & 289.8880 & 3.23 & 0.01503 & 7.72 \\
3 & 462,844 & 0.0223 & 1.08 & 281.1345 & 0.42 & 0.01396 & 0.12 \\
4 & 923,844 & 0.0220 & - & 279.6317 & - & 0.01393 & - \\
\hline
\end{tabular}

${ }^{*} N_{S}=T_{\text {in }} \cdot S_{\text {gen }} / Q, T_{\text {in }}$ is the temperature at inlet, $S_{\text {gen }}$ is the total entropy generation and $Q$ is the heat input.

From the table, it can be observed that the relative discrepancy of friction factor, Nusselt number and dimensionless total entropy generation are $1.08 \%, 0.42 \%, 0.12 \%$ respectively, when the mesh changes from mesh 3 to mesh 4 . Therefore, mesh 3 with 462,844 nodes is adopted by considering the balance of accuracy and efficiency. To validate the numerical approach, the results of base fluid in terms of fluid friction and heat transfer are compared with that obtained by Petukhov's correlation, Equation (24), and Gnielinski's correlation, Equation (25), which are given as [50]:

$$
\begin{gathered}
f=(0.790 \ln \operatorname{Re}-1.64)^{-2}, \\
N u=\frac{(f / 8)(\operatorname{Re}-1000) \operatorname{Pr}}{1+12.7(f / 8)^{0.5}\left(\operatorname{Pr}^{2 / 3}-1\right)},
\end{gathered}
$$

and the comparisons are shown separately in Figures 2 and 3.

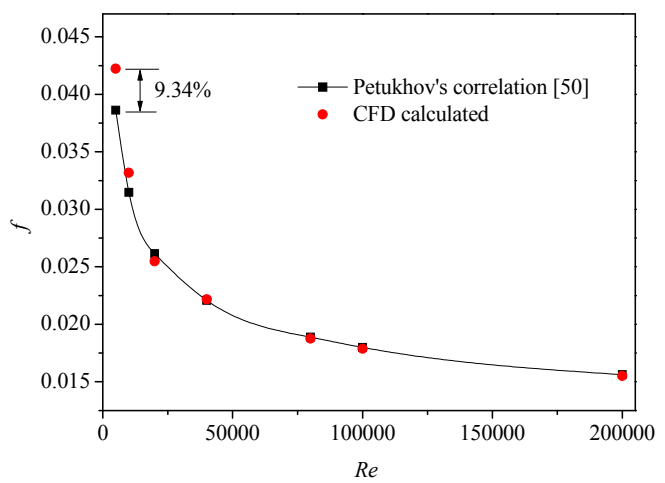

Figure 2. Validation of CFD calculated friction factor with Petukhov's correlation [50].

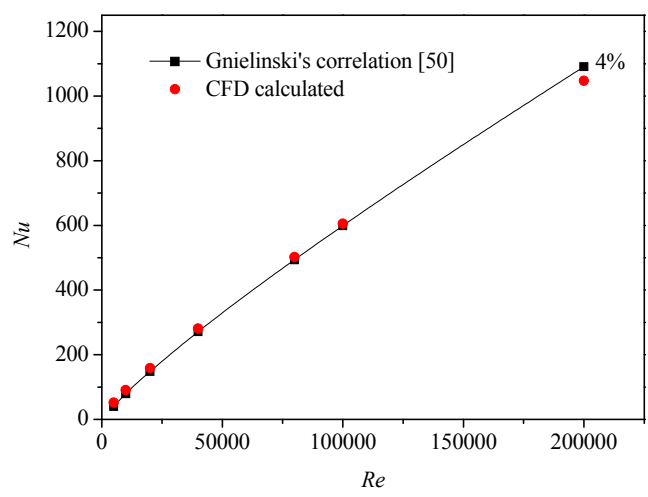

Figure 3. Validation of CFD calculated Nusselt number with Gnielinski's correlation [50].

From these figures, it can be seen that the CFD calculated results are in good agreement with the correlation in a wide range of Reynolds number except a few deviations, i.e., $9.34 \%$ of friction factor at $R e=5000$ and $4 \%$ of Nusselt number at $R e=200,000$. 
Additionally, the model of entropy generation rate is validated against the results derived by Bejan's formula, i.e., Equation (26). The formula is an analytical expression applied to the determination of entropy generation in a tube with forced convective heat transfer and reads as [51]:

$$
S_{\text {gen }}^{\prime}=\frac{q^{\prime 2}}{\pi \lambda T_{b u l k}^{2} N u}+\frac{8 m^{3} c_{f}}{\pi^{2} \rho^{2} T_{b u l k} D^{5}}
$$

where $q^{\prime}$ is the heat input per unit length, $D$ is the diameter of tube, $N u=h D / \lambda$ with $h=q /\left(T_{w}-T_{b u l k}\right)$, $m$ is the mass flow rate, $c_{f}=(-\mathrm{d} p / \mathrm{d} x) /\left(\rho u^{2} / 2\right)$ with $u=4 m /\left(\pi \rho d^{2}\right)$ and $T_{b u l k}$ is the bulk fluid temperature, which takes the approximate value as $\left(T_{\text {in }}+T_{\text {out }}\right) / 2$. The validation of this term is shown in Figure 4. From the figure, it can be observed that good agreement is reached between present entropy generation model and Bejan's formula.

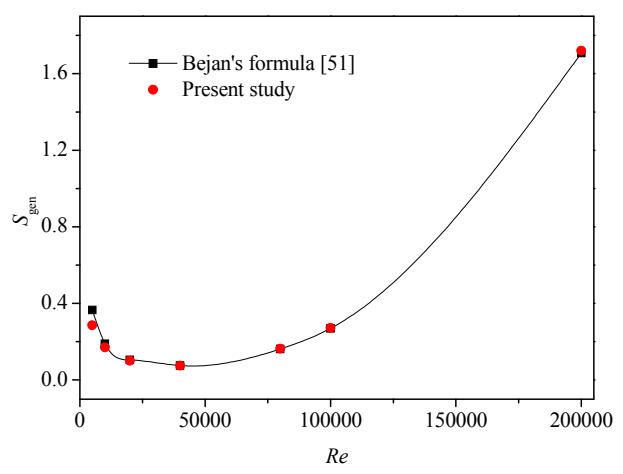

Figure 4. Validation of present entropy generation model with Bejan's formula [51].

\subsection{Local Entropy Generation Profile}

To make the comparison of local entropy generation more appropriate, the dimensionless volumetric entropy generation rate in the flow region of heated pipe flow characterizing the ratio of energy dissipation and the heat input under the local conditions is defined as:

$$
\dot{S}_{\text {gen }}^{+}=\frac{\dot{S}_{\text {gen }}^{\prime \prime \prime} T \cdot \frac{\pi d^{2}}{4} l}{q \cdot \pi d l}=\frac{\dot{S}_{\text {gen }}^{\prime \prime \prime} T d}{4 q},
$$

in which, $T$ is the local temperature, $q$ is the heat flux and $l$ is the length of the tube.

Figure 5 shows the dimensionless local entropy generation by direct dissipation, turbulent dissipation, mean temperature gradients and fluctuating temperature gradients at different Reynolds number, in which the fluids with nanoparticle concentration of $0 \%, 1 \%, 2 \%, 4 \%$ and $6 \%$ are taken into account. From these figures, the peak value of the four terms can be found in the flow domain. However, the peak value of entropy generation from mean gradients, i.e., $\dot{S}_{\text {gen, } \overline{\mathrm{D}}}^{+}$and $\dot{S}_{\text {gen, }}^{+}$, exist in the viscous sublayer $\left(y^{+}<5\right)$ due to steep gradients here $(\partial \bar{u} / \partial y$ and $\partial \bar{T} / \partial y)$, while the peak value of entropy generation from fluctuation, i.e., $\dot{S}_{\text {gen, } \mathrm{D}^{\prime}}^{+}$and $\dot{S}_{\text {gen, } \mathrm{C}^{\prime}}^{+}$, lie in the buffer layer, inner edge of buffer layer accurately $\left(y^{+} \sim 10\right)$ because of violent turbulence here. In a detailed view, the entropy generation by direct dissipation decreases monotonously when $y^{+}$increases, but the term owing to the turbulence dissipation grows rapidly form 0 to its peak value in the sublayer to inner edge of buffer layer, and then reduced gradually when $y^{+}$increases unceasingly. Similar results are found in the distribution of entropy generation by mean and fluctuating temperature gradients, but some difference exists in the near wall region. The entropy generation due to mean temperature gradients hardly changes or with some small rise in the sublayer to inner edge of buffer layer, and the value of water is greater than that of other nanofluids, while no discrepancy for the value of entropy generation by fluctuating temperature gradients existed in the sublayer when the concentration of nanoparticle increases. 
Additionally, the profiles with self-similarity of these terms show that the entropy generation by dissipation, including direct dissipation and turbulent dissipation, grows greatly, while the entropy generations due to both mean and fluctuating temperature gradients remain the almost same state as Reynolds number of the pipe flow increases. It can also be seen that the local entropy generation resulted from friction increases and the terms due to heat transfer decreases as the nanofluids become denser and denser from Figure 5, which is due to the increase of viscosity and improvement of thermal conductivity.
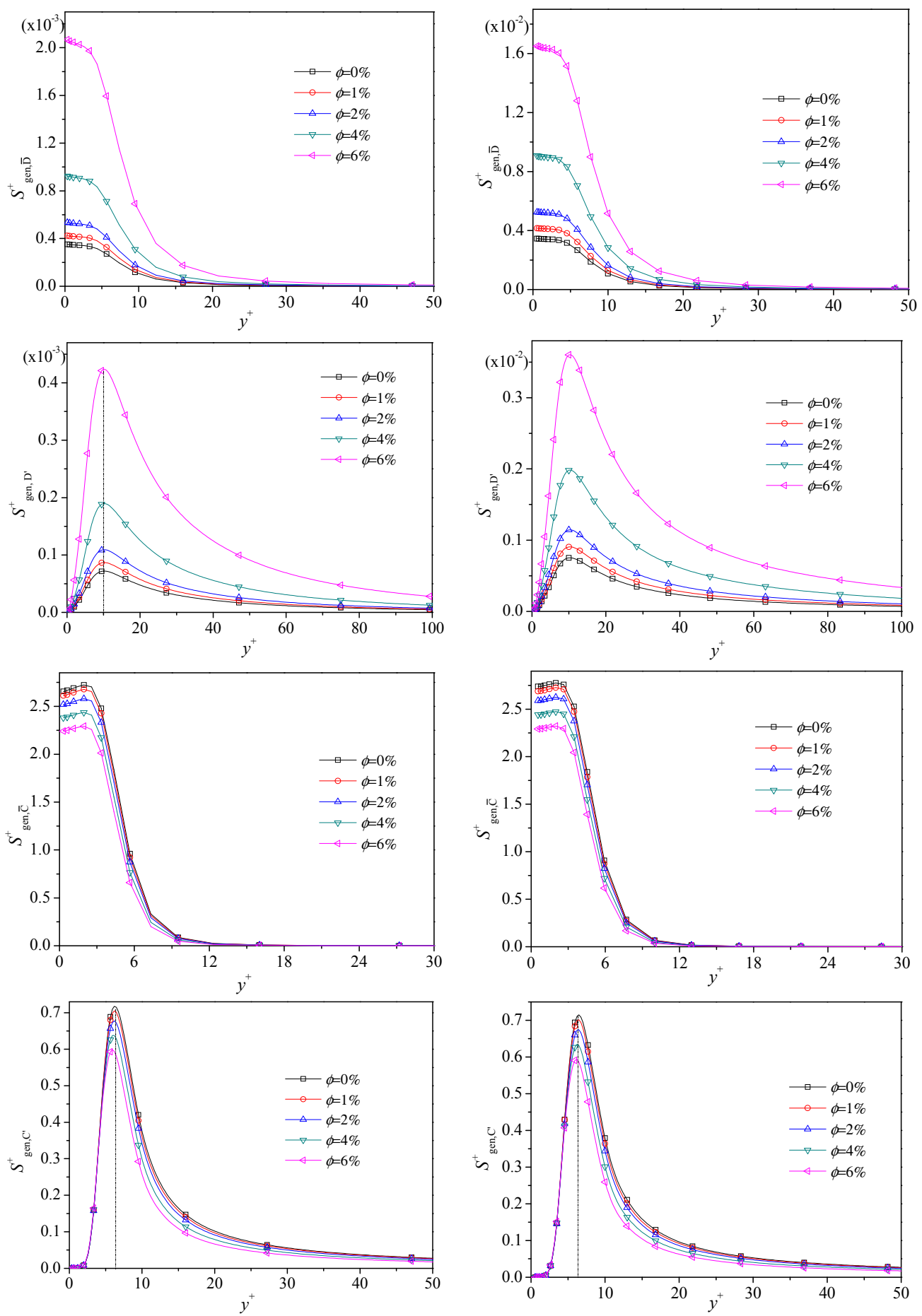

(a)

(b)

Figure 5. Cont. 

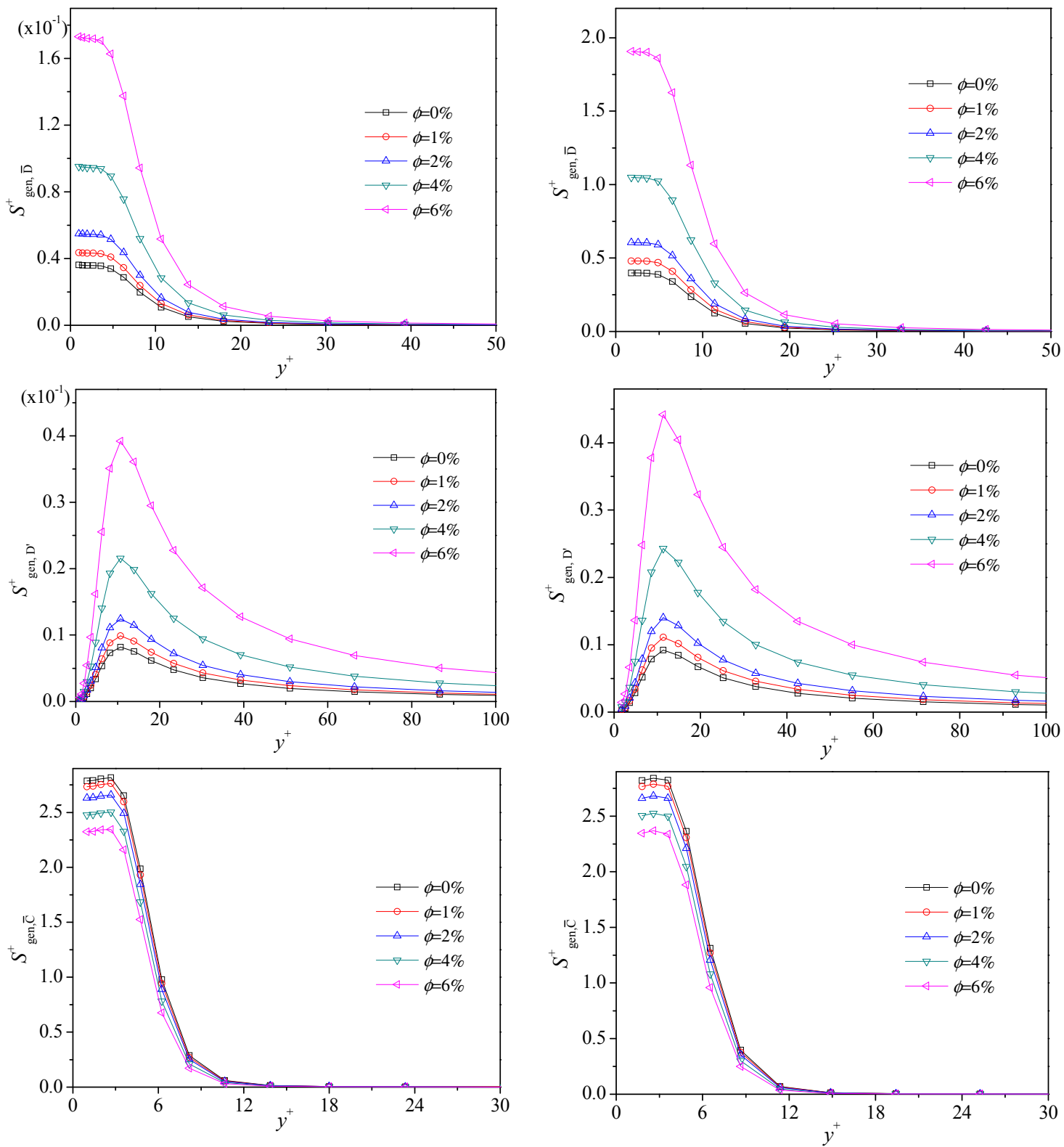

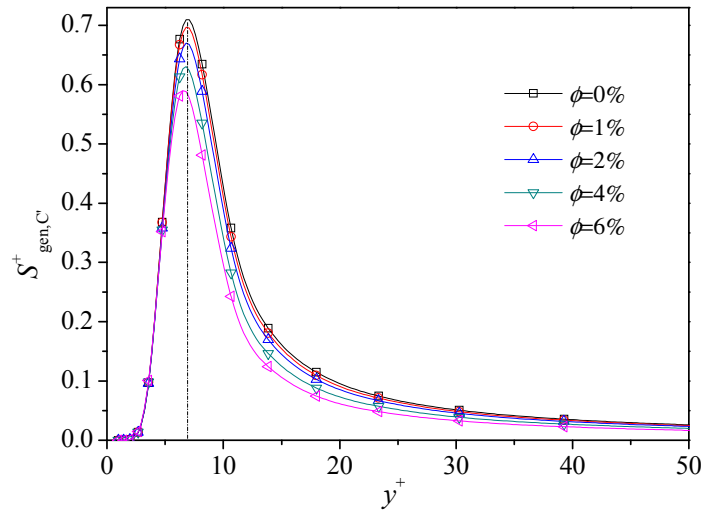

(c)

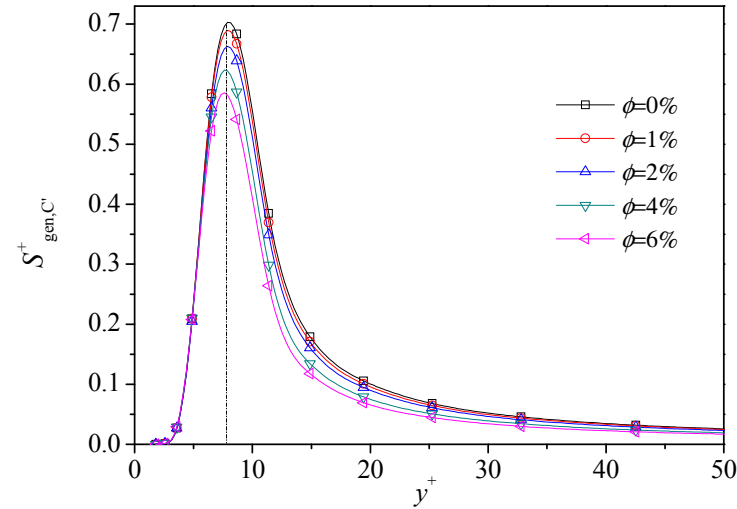

(d)

Figure 5. Dimensionless local entropy generation by direct dissipation, turbulence dissipation, mean temperature gradients and fluctuating temperature gradients at different Reynolds number; (a) $R e=5000 ;$ (b) $R e=10,000$; (c) $R e=20,000$; (d) $R e=40,000$ (The dimensionless local entropy generation here has been quadrupled). 


\subsection{Thermodynamic Irreversilities}

The total entropy generation rate represents the availability of engineering process or energy system to some degree. To make the form of this item more appropriate for analysis, the dimensionless entropy generation which represents the ratio of energy dissipated to the total heat transfer, is redefined as:

$$
N_{\mathrm{s}}=\frac{S_{\text {gen }} T_{\mathrm{b}}}{Q}
$$

in which, $S_{\text {gen }}, T_{\mathrm{b}}$ and $Q$ are entropy generation in the fluid domain, bulk temperature of nanofluids and heat input to the tube respectively.

Based on the analysis above, the main entropy generations come from two irreversibilities, heat transfer and fluid friction. The two irreversibilities vary oppositely most time, as one increases the other decreases. Therefore, the proportion of entropy generation by heat transfer in the total entropy generation is an important parameter for thermal processes, and the dimensionless Bejan number $(\mathrm{Be})$ is defined to describe the share [37]:

$$
B e=\frac{S_{\text {gen,C }}}{S_{\text {gen }}} .
$$

The limiting values of $B e=0$ and $B e=1$ mean that the entropy generation is dominated by fluid friction irreversibility and heat transfer irreversibility respectively.

Figure 6 shows the variation of dimensionless entropy generation rate with Reynolds number corresponding to different heat flux at the tube wall, from which it can be observed that this term decreases first and then rise when Reynolds number increases from 5000 to 200,000 for all heat conditions. Besides, there exist the intersection points for water and four nanofluids. The entropy generations decrease before the intersection, while increase after the intersection as the increase of particle concentration. The accompanying increase of entropy generation indicates that the heat transfer enhancement by means of nanofluids is an inadvisable approach from the viewpoint of entropy generation minimization method (EGM). This is due to the irreversibilities are thermal dominated first and friction dominated later. In addition, the entropy generation is smaller at low Reynolds number than that at high Reynolds number when the heat flux is low, such as Figure 6a,b. Then the two terms match as the heat flux increases, shown in Figure 6c. Subsequently, the entropy generation at low Reynolds number becomes greater than that at high Reynolds number oppositely when the heat flux is high enough, as shown in Figure 6d. Moreover, the figures also indicate that the Reynolds number corresponding to minimum entropy generation increases as heat flux increases.

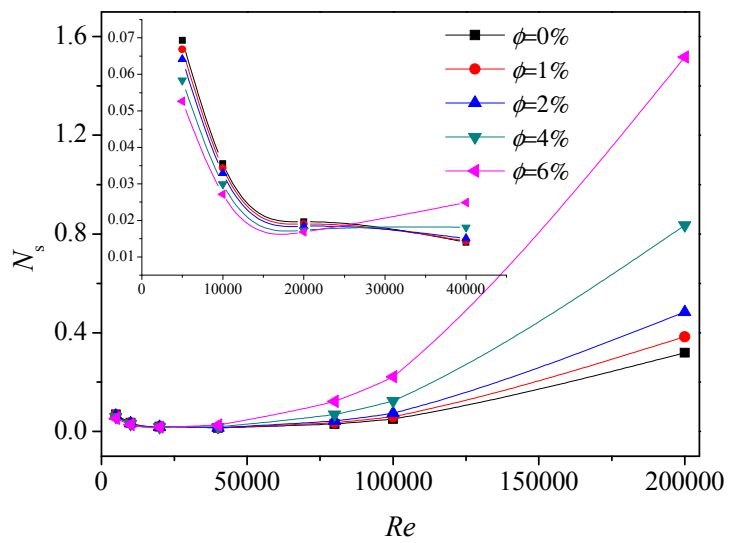

(a)

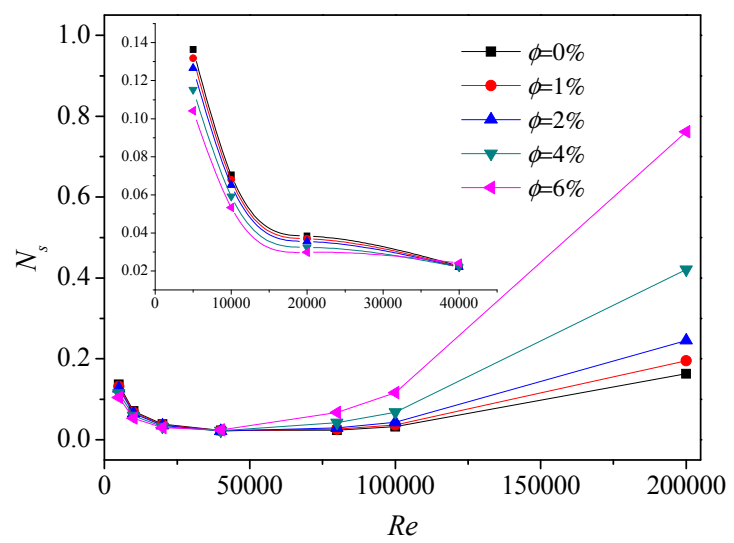

(b)

Figure 6. Cont. 


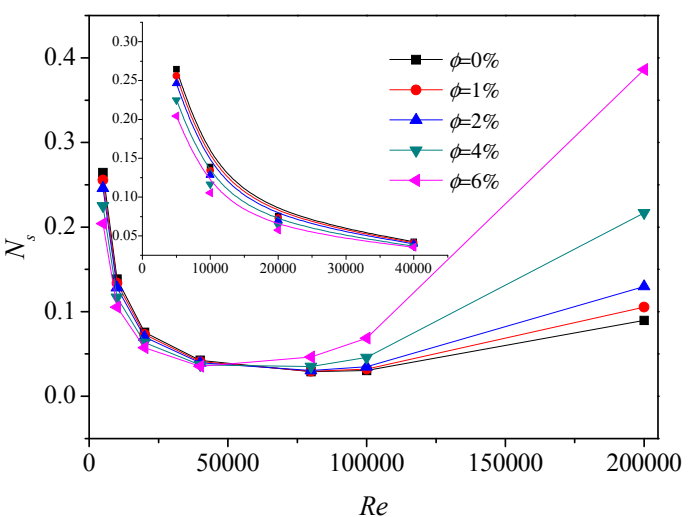

(c)

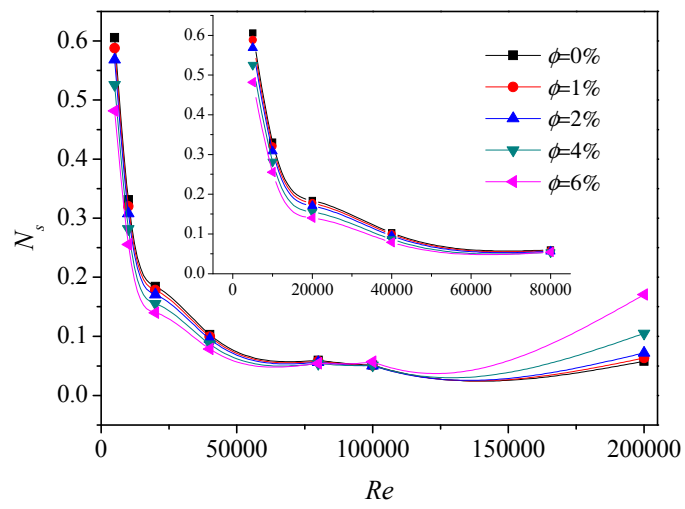

(d)

Figure 6. Variation of dimensionless entropy generation rate with Reynolds number and nanoparticle concentration corresponding to different heat flux enforced at the tube wall; (a) $q=50,000 \mathrm{~W} / \mathrm{m}^{2}$; (b) $q=100,000 \mathrm{~W} / \mathrm{m}^{2} ;$ (c) $q=200,000 \mathrm{~W} / \mathrm{m}^{2}$; (d) $q=500,000 \mathrm{~W} / \mathrm{m}^{2}$.

Figure 7 shows the variation of Bejan number with Reynolds number and volume fraction of nanoparticle corresponding to different heat flux. From the figure, it can be seen that an increase of particle concentration and Reynolds number reduces the thermal irreversibility significantly, while the augmentation of heat flux increases the thermal irreversibility dramatically, especially in the high Reynold number conditions. For the situations whose $B e$ is close to 0 , the enhancement of heat transfer through higher Reynolds number or denser nanofluids is undesirable for its more fluid friction irreversibility, which is consistent with the results derived by Figure 6 .

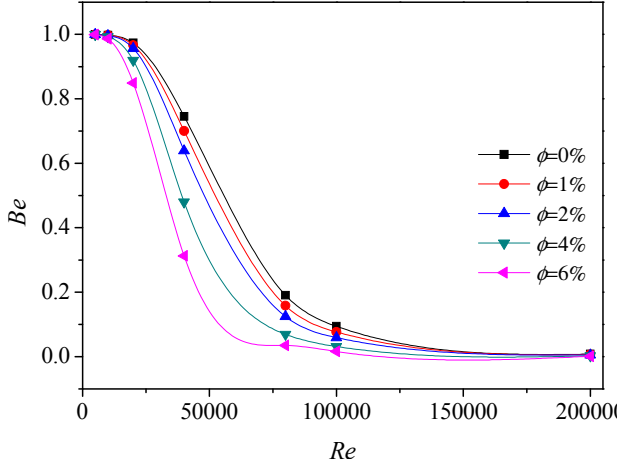

(a)

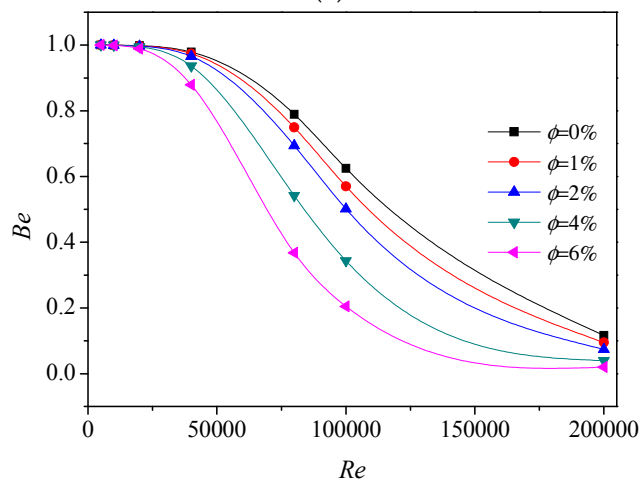

(c)

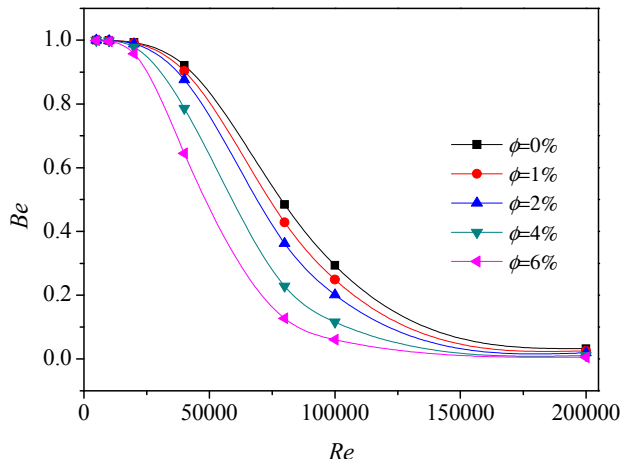

(b)

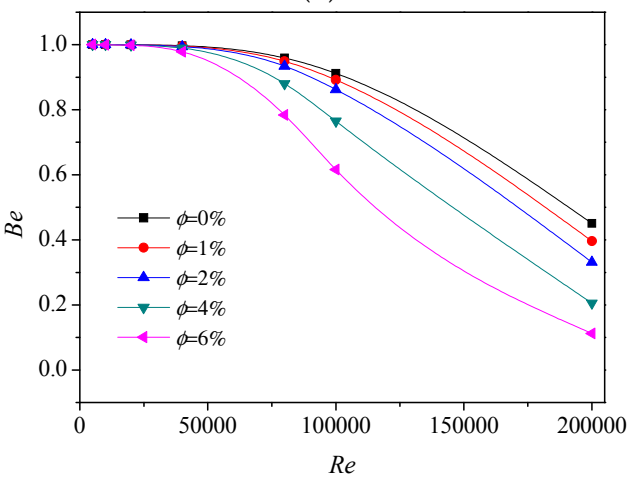

(d)

Figure 7. Variation of Bejan number with Reynolds number and volume fraction of nanoparticle corresponding to different heat flux enforced at the tube wall; (a) $q=50,000 \mathrm{~W} / \mathrm{m}^{2}$; (b) $q=100,000 \mathrm{~W} / \mathrm{m}^{2} ;$ (c) $q=200,000 \mathrm{~W} / \mathrm{m}^{2} ;$ (d) $q=500,000 \mathrm{~W} / \mathrm{m}^{2}$. 


\subsection{Performance Evaluation}

The location of minimum entropy generation is preferable, but the state does not correspond to the best heat transfer condition possibly. Therefore, the evaluation parameter of $E_{\mathrm{p}}$, which combines the first law and second law of thermodynamics and attributed to assess the actual performance of heat transfer, is defined as:

$$
E_{\mathrm{p}}=\frac{N u}{N_{\mathrm{s}}}
$$

where $N u$ is the Nusselts number of convective heat transfer, and $N_{\mathrm{s}}$ is the dimensionless entropy generation stated above. Therefore, this evaluation parameter characterizes the heat transfer capability per unit entropy generation.

To analyze the effect of adding nanoparticles to base fluid, the $E_{\mathrm{p}}$ criterion is adopted. Figure 8 illustrates the performance of the nanofluids as a function of Reynolds number with different heat flux at the wall. From which, it can be noted that there exist the peak values representing the optimal state for all nanofluids no matter what heat conditions, and the peak value reduces significantly as the volume fraction of nanoparticles increases. Besides, the decrease of volume fraction and increase of heat flux lead to the growth of $R e_{\mathrm{op}}$, which is the Reynolds number corresponding to the peak value of $E_{\mathrm{p}}$. The intersection points are also found in the figures. Taking the nanofluid of $6 \mathrm{vol} \%$ nanoparticles and water as an example, the intersection Reynolds number, or called advisable Reynolds number $R e_{\mathrm{ad}}$ increases synchronously as heat flux increases. When the $R e$ is less than $R e_{\mathrm{ad}}$, the addition of nanoparticles actually improve the performance of heat transfer, but if the $R e$ is greater than $R e_{\mathrm{ad}}$ the penalty of $E_{\mathrm{p}}$ occurs by using nanofluids, which is due to the results of viscosity increase is much stronger than the improvement of thermal conductivity. So do other cases.

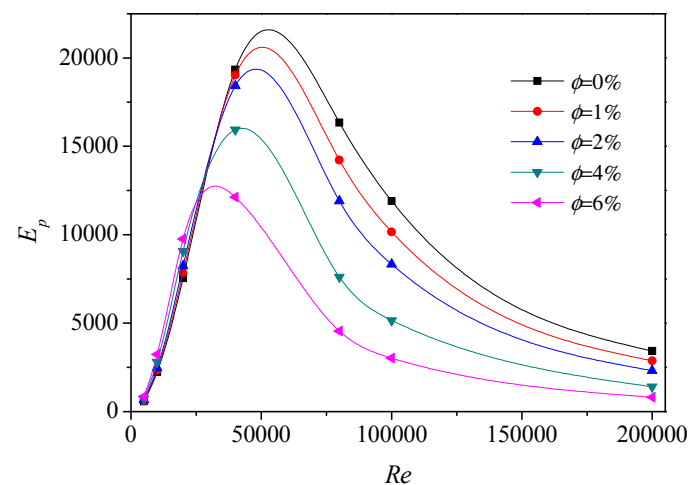

(a)

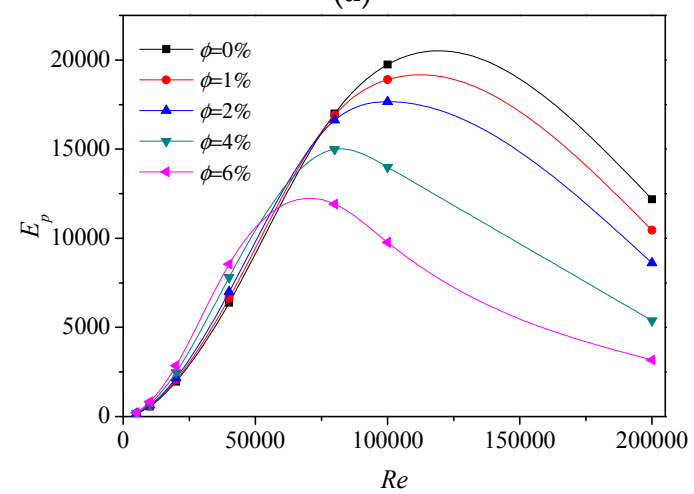

(c)

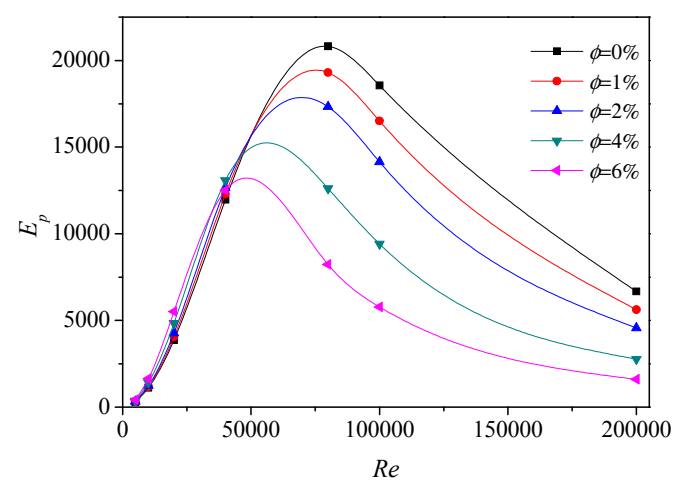

(b)

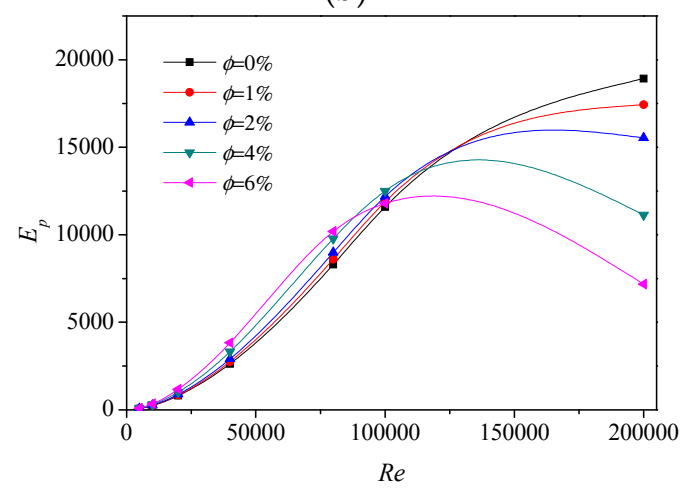

(d)

Figure 8. Performance of the nanofluids as a function of Reynolds number with different heat flux enforced at the wall; (a) $q=50,000 \mathrm{~W} / \mathrm{m}^{2}$; (b) $q=100,000 \mathrm{~W} / \mathrm{m}^{2}$; (c) $q=200,000 \mathrm{~W} / \mathrm{m}^{2}$; (d) $q=500,000 \mathrm{~W} / \mathrm{m}^{2}$. 
Figure 9 shows the variation of $E_{\mathrm{p}}$ with particle concentration at some fixed Reynolds number. From these figures, it can be observed that the performance is improved at low or medium $R e$, while deteriorated at high $R e$ as nanofluids is denser and denser when the heat flux is $50,000 \mathrm{~W} / \mathrm{m}^{2}$, as shown in Figure 9a. Moreover, the performance of $R e=50,000$ is the best among the five Reynolds conditions on most occasions, and the performance of $R e=150,000$ is just slightly better than that of $R e=5000$. The possible reason can be concluded as that the flow of $R e=150,000$ causes much more entropy generation by turbulent dissipation. Intersection points are found in the figure as well, that is the intersection of the $E_{\mathrm{p}}$ curve of $R e=25,000$ and the $E_{\mathrm{p}}$ curve of $R e=50,000$ at $\phi=0.047$, and the intersection of the $E_{\mathrm{p}}$ curve of $R e=25,000$ and the $E_{\mathrm{p}}$ curve of $R e=100,000$ at $\phi=0.005$, which mean that performances are same here. Before the intersection, the performance of higher Re is better than that of lower $R e$, but this becomes opposite after the intersection, i.e., the performance of lower $R e$ is better than that of higher Re. The same phenomena can be found in the remained photos of Figure 9 . Therefore, the work here provides the advisable particle concentration range to the enhanced heat transfer processes for the given Reynolds number.

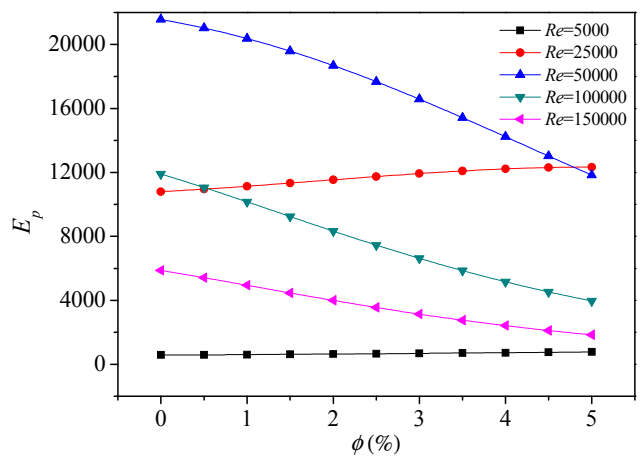

(a)

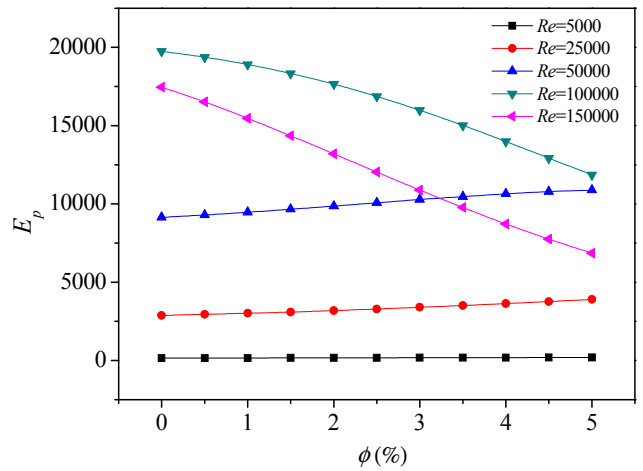

(c)

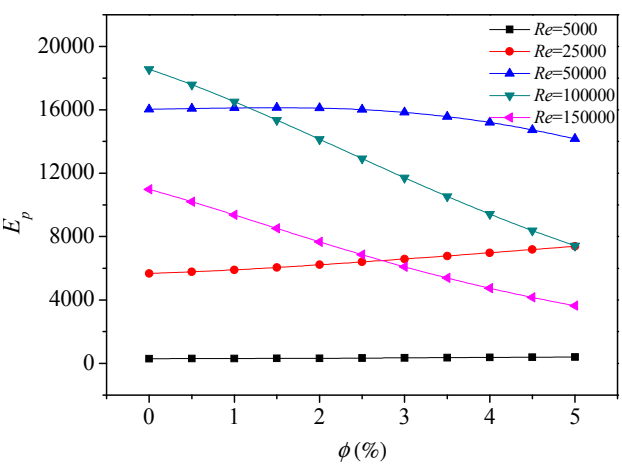

(b)

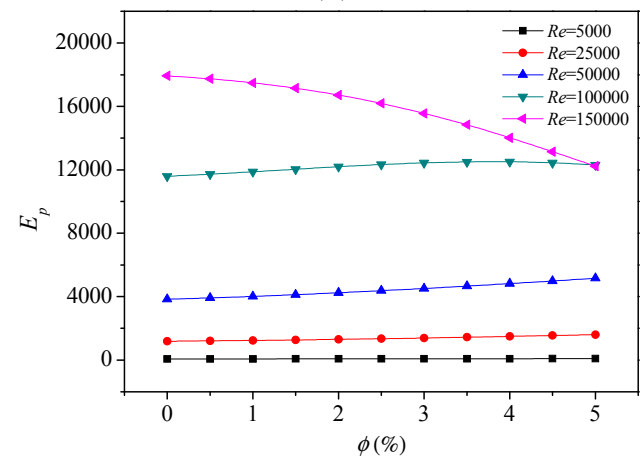

(d)

Figure 9. Performance evaluation of the nanofluids as a function of particle concentration with different heat flux enforced at the wall; (a) $q=50,000 \mathrm{~W} / \mathrm{m}^{2}$; (b) $q=100,000 \mathrm{~W} / \mathrm{m}^{2}$; (c) $q=200,000 \mathrm{~W} / \mathrm{m}^{2}$; (d) $q=500,000 \mathrm{~W} / \mathrm{m}^{2}$.

\section{Conclusions}

In this paper, an entropy generation analysis of turbulent convective heat transfer to nanofluids is carried out through numerical simulation. The standard $k-\omega$ model is adopted for turbulence closure and the entropy generation model is established based on the second law of thermodynamics. The numerical approach is validated against the Petukhov's correlation and Gnielinski's correlation with regards to the friction factor and Nusselt number, as well as the analytical expression proposed by Bejan characterizing the entropy generation rate. In addition, the local entropy generation profile within the flow domain, and the general assessment of thermal irreversibilities as well as performance 
evaluation of different conditions are also investigated. The main inferences can be summarized as follows:

(1) Peak values of local entropy generation due to the mean parameters exist in the viscous sublayer $\left(y^{+} \sim 5\right)$, while those due to fluctuating parameters lie in the buffer layer $\left(y^{+}>10\right)$ for all nanofluids at different Reynolds number.

(2) Intersection points of total entropy generations for water and other nanofluids have been observed, where the total irreversibilities are equal. The entropy generations decrease before the intersection while increase after the intersection as particle concentration increases, when the heat transfer enhancement through nanofluids is an inadvisable approach from an EGM viewpoint.

(3) The Bejan number, which determines whether the irreversibilities due to heat transfer are dominant, is shown to decrease as the Re increases, particle concentration increases and heat flux reduces.

(4) By definition of the evaluation parameter of $E_{\mathrm{p}}$, the optimal Reynolds number $R e_{\mathrm{op}}$ and the advisable Reynolds number $R e_{\mathrm{ad}}$ can be determined. The decrease of particle concentration and increase of heat flux lead to the growth of $R e_{\mathrm{op}}$. Besides, if $R e<R e_{\mathrm{ad}}$, the further addition of nanoparticles improves the performance of heat transfer, but if $R e>R e_{\mathrm{ad}}$, the penalty of $E_{\mathrm{p}}$ occurs.

Acknowledgments: This work is supported by the Foundation for Innovative Research Groups of the National Natural Science Foundation of China (NSFC, Grant No. 51421063) and the National Natural Science Foundation of China (NSFC, Grant No. 51536001, 51572058).

Author Contributions: Then research concept was proposed by Yu Ji and Hao-Chun Zhang initially. Yu Ji performed the calculation under the help of Xie Yang and Lei Shi. The manuscript was primarily written by Yu Ji, with the assistance of Hao-Chun Zhang and Lei Shi. All authors have read and approved the final manuscript.

Conflicts of Interest: The authors declare no conflict of interest.

\section{Nomenclature}

Be Bejan number

$c_{p} \quad$ specific heat capacity at constant pressure, $\mathrm{J} / \mathrm{kg} \cdot \mathrm{K}$

$C_{\mu} \quad$ parameter in the turbulent model

$E_{p}$ evaluation of performance

$k$ turbulent kinetic energy, $\mathrm{m}^{2} / \mathrm{s}^{2}$

$N_{s}$ dimensionless entropy generation rate

$\mathrm{Nu}$ Nusselts number

$P \quad$ mean pressure, $\mathrm{Pa}$

$\mathrm{Pr}_{t}$ turbulent Prandtl number

$q$ heat flux, $\mathrm{W} / \mathrm{m}^{2}$

Re Reynolds number

$S$ entropy generation rate, $\mathrm{W} / \mathrm{m} \cdot \mathrm{K}$

$T$ temperature, $\mathrm{K}$

$u \quad$ velocity, $\mathrm{m} / \mathrm{s}$

$V \quad$ volume of fluid domain, $\mathrm{m}^{3}$

\section{Greek Letters}

$\alpha^{*} \quad$ coefficient in the turbulence model

$\alpha_{t} \quad$ turbulent thermal diffusivity, $\mathrm{m}^{2} / \mathrm{s}$

$\Delta \quad$ medium variable calculating thermodynamic of nanofluids, $\mathrm{W}^{2} / \mathrm{m}^{2} \cdot \mathrm{K}^{2}$

$\varepsilon \quad$ turbulent energy dissipated per unit mass, $\mathrm{m}^{2} / \mathrm{s}^{3}$

$\lambda$ thermal conductivity, $\mathrm{W} / \mathrm{m} \cdot \mathrm{K}$

$\mu \quad$ viscosity, $\mathrm{kg} / \mathrm{m} \cdot \mathrm{s}$

$\rho$ density, $\mathrm{kg} / \mathrm{m}^{3}$

$\phi \quad$ particle concentration

$\omega$ specific dissipation rate, $1 / \mathrm{s}$ 


\section{Subscripts and Superscripts}

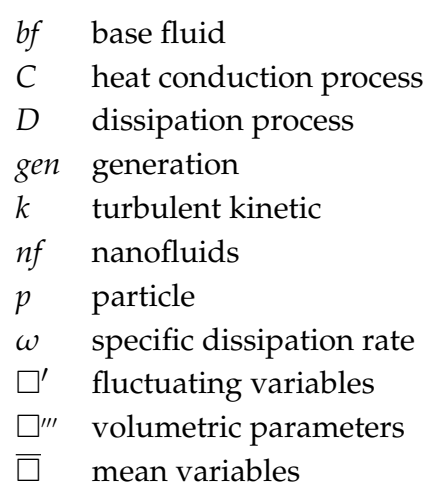

\section{Abbreviations}

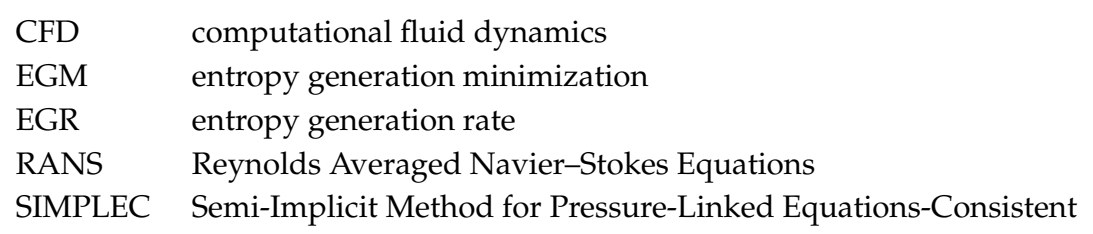

\section{References}

1. Choi, S.U.S. Enhancing Thermal Conductivity of fluids with Nanoparticles. Dev. Appl. Non-Newton. Flows FED/MD 1995, 231, 99-105.

2. Kakac, S.; Pramuanjaroenkij, A. Review of convective heat transfer enhancement with nanofluids. Int. J. Heat Mass Transf. 2009, 52, 3187-3196. [CrossRef]

3. He, Y.R.; Jin, Y.; Chen, H.S.; Ding, Y.L.; Cang, D.Q.; Lu, H.L. Heat transfer and flow behavior of aqueous suspensions of $\mathrm{TiO}_{2}$ nanoparticles (nanofluids) flowing upward through a vertical pipe. Int. J. Heat Mass Transf. 2007, 50, 2272-2281. [CrossRef]

4. Xuan, Y.M.; Li, Q. Investigation on convective heat transfer and flow features of nanofluids. J. Heat Transf. 2003, 125, 151-155. [CrossRef]

5. Li, Q.; Xuan, Y.M. Convective heat transfer and flow characteristic of Cu-water nanofluid. Sci. China Ser. E 2002, 45, 408-416.

6. Xuan, Y.M.; Roetzel, W. Conceptions for heat transfer correlation of nanofluids. Int. J. Heat Mass Transf. 2000, 43, 3701-3707. [CrossRef]

7. Rea, U.; Mckrell, T.; Hu, L.W.; Buongiorno, J. Laminar convective heat transfer and viscous pressure loss of alumina-water and zirconia-water nanofluids. Int. J. Heat Mass Transf. 2009, 52, 2042-2048. [CrossRef]

8. Maiga, S.E.B.; Palm, S.J.; Nguyen, C.T.; Roy, G.; Galanis, N. Heat transfer enhancement by using nanofluids in forced convection flows. Int. J. Heat Fluid Flow 2005, 26, 530-546. [CrossRef]

9. Bianco, V.; Manca, O.; Nardini, S. Numerical investigation on nanofluids turbulent convection heat transfer inside a circular tube. Int. J. Therm. Sci. 2011, 50, 341-349. [CrossRef]

10. Pantzali, M.N.; Kanaris, A.G.; Antoniadis, K.D.; Mouza, A.A.; Paras, S.V. Effect of nanofluids on the performance of miniature plate heat exchanger with modulated surface. Int. J. Heat Fluid Flow 2009, 30, 691-699. [CrossRef]

11. Nguyen, C.T.; Roy, G.; Gauthier, C.; Galanis, N. Heat transfer enhancement using $\mathrm{Al}_{2} \mathrm{O}_{3}$-water nanofluid for an electronic liquid cooling system. Appl. Therm. Eng. 2007, 27, 1501-1506. [CrossRef]

12. Tsai, T.H.; Chein, R.Y. Performance analysis of nanofluid-cooled micro channel heat sinks. Int. J. Heat Fluid Flow 2007, 28, 1013-1026. [CrossRef]

13. Li, P.; Xie, Y.; Zhang, D.; Xie, G.N. Heat transfer enhancement and entropy generation of nanofluids laminar convection in microchannels with flow control devices. Entropy 2016, 18, 134. [CrossRef]

14. Bianco, V.; Manca, O.; Nardini, S. Second law analysis of $\mathrm{Al}_{2} \mathrm{O}_{3}$-water nanofluid turbulent forced convection in a circular cross section tube with constant wall temperature. Adv. Mech. Eng. 2013. [CrossRef] 
15. Chon, C.H.; Kihm, K.D. Thermal conductivity enhancement of nanofluids by Brownian motion. J. Heat Transf. 2005, 127, 810. [CrossRef]

16. Yu, C.J.; Richter, A.G.; Datta, A.; Durbin, M.K.; Dutta, P. Observation of molecular layering in thin liquid films using X-ray reflectivity. Phys. Rev. Lett. 1999, 82, 2326-2329. [CrossRef]

17. Keblinski, P.; Phillpot, S.R.; Choi, S.U.S.; Eastman, J.A. Mechanisms of heat flow in suspensions of nano-sized particles (nanofluids). Int. J. Heat Mass Transf. 2002, 45, 855-863. [CrossRef]

18. Yu, W.; Choi, S.U.S. The role of interfacial layers in the enhanced thermal conductivity of nanofluids: A renovated Maxwell model. J. Nanopart. Res. 2003, 5, 167-171. [CrossRef]

19. Ding, Y.L.; Wen, D.S. Particle migration in a flow of nanoparticle suspensions. Powder Technol. 2005, 149, 84-92. [CrossRef]

20. Mwesigye, A.; Huan, Z.J. Thermodynamics analysis and optimization of fully developed turbulent forced convection in a circular tube with water- $\mathrm{Al}_{2} \mathrm{O}_{3}$ nanofluid. Int. J. Heat Mass Transf. 2015, 89, $694-706$. [CrossRef]

21. Bejan, A. A study of entropy generation in fundamental convective heat transfer. J. Heat Transf. 1979, 101, 718-725. [CrossRef]

22. Ji, Y.; Zhang, H.C.; Tong, J.F.; Wang, X.W.; Wang, H.; Zhang, Y.N. Entropy assessment on direct contact condensation of subsonic steam jets in a water tank through numerical investigation. Entropy 2016, 18, 21. [CrossRef]

23. Herwig, H.; Wenterodt, T. Second Law Analysis of Momentum and Heat Transfer in Unit Operations. Int. J. Heat Mass Transf. 2011, 54, 1323-1330. [CrossRef]

24. Schmandt, B.; Herwig, H. Loss Coefficients in Laminar Flows: Essential for the Design of Micro Flow Systems. PAMM 2011, 11, 27-30. [CrossRef]

25. Jin, Y.; Herwig, H. Turbulent flow and heat transfer in channels with shark skin surfaces: Entropy generation and its physical significance. Int. J. Heat Mass Transf. 2014, 70, 10-22. [CrossRef]

26. Goudarzi, N.; Talebi, S. Improving performance of two-phase natural circulation loops by reducing of entropy generation. Energy 2015, 93, 882-899. [CrossRef]

27. Khalkhali, H.; Faghri, A.; Zuo, Z.J. Entropy generation in a heat pipe system. Appl. Therm. Eng. 1999, 19, 1027-1043. [CrossRef]

28. Myat, A.; Thu, K.; Kim, Y.D.; Chakraborty, A.; Chun, W.G.; Ng, K.C. A second law analysis and entropy generation minimization of an absorption chiller. Appl. Therm. Eng. 2011, 31, 2405-2413. [CrossRef]

29. Singh, P.K.; Anoop, T.; Sundararajan, T.; Das, S.K. Entropy generation due to flow and heat transfer in nanofluids. Int. J. Heat Mass Transf. 2010, 53, 4757-4767. [CrossRef]

30. Bianco, V.; Manca, O.; Nardini, S. Entropy generation analysis of turbulent convection flow of $\mathrm{Al}_{2} \mathrm{O}_{3}$ nanofluid in a circular tube subjected to constant wall heat flux. Energy Convers. Manag. 2014, 77, 306-314. [CrossRef]

31. Siavashi, M.; Jamali, M. Heat transfer and entropy generation analysis of turbulent flow of $\mathrm{TiO}_{2}-\mathrm{water}$ nanofluid inside annuli with different radius ratios using two-phase mixture model. Appl. Therm. Eng. 2016, 100, 1149-1160. [CrossRef]

32. Kuppusamy, N.R.; Mohammed, H.A.; Lim, C.W. Numerical investigation of trapezoidal grooved microchannel heat sink using nanofluids. Thermochim. Acta 2013, 573, 39-56. [CrossRef]

33. Roy, G.; Nguyen, C.T.; Lajoie, P.R. Numerical investigation of laminar flow and heat transfer in a radial flow cooling system with the use of nanofluids. Superlattices Microstruct. 2004, 35, 497-511. [CrossRef]

34. Duangthongsuk, W.; Wongwises, S. An experimental study on the heat transfer performance and pressure drop of $\mathrm{TiO}_{2}$-water nanofluids flowing under a turbulent flow regime. Int. J. Heat Mass Transf. 2010, 53, 334-344.

35. Akbari, M.; Galanis, N.; Behzadmehr, A. Comparative assessment of single and two-phase models for numerical studies of nanofluid turbulent forced convection. Int. J. Heat Fluid Flow 2012, 37, 136-146. [CrossRef]

36. Li, P.; Zhang, D.; Xie, Y.H. Heat transfer and flow analysis of $\mathrm{Al}_{2} \mathrm{O}_{3}$-water nanofluids in microchannel with dimple and protrusion. Int. J. Heat Mass Transf. 2014, 73, 456-467. [CrossRef]

37. Pinto, R.V.; Fiorelli, F.A.S. Review of the mechanisms responsible for heat transfer enhancement using nanofluids. Appl. Therm. Eng. 2016, 108, 720-739. [CrossRef] 
38. Rabiee, A.; Atf, A. A computational fluid dynamics investigation of various nanofluids in a boiling flow field. Prog. Nucl. Energy 2017, 95, 61-69. [CrossRef]

39. Wang, X.; Xu, X.S.; Choi, S.U. Thermal conductivity of nanoparticle-fluid mixture. J. Thermophys. Heat Transf. 1999, 13, 474-480. [CrossRef]

40. Brinkman, H.C. The viscosity of concentrated suspensions and solutions. J. Chem. Phys. 1952, 20, 571-581. [CrossRef]

41. Batchelor, G.K. The effect of Brownian motion on the bulk stress in a suspension of spherical particles. J. Fluid Mech. 1977, 83, 97-117. [CrossRef]

42. Khanafer, K.; Vafai, K. A critical synthesis of thermophysical characteristics of nanofluids. Int. J. Heat Mass Transf. 2011, 54, 4410-4428. [CrossRef]

43. Bruggeman, D.A.G. Berechnung verschiedener physikalischer Konstanten von heterogenen Substanzen. I. Dielektrizitätskonstanten und Leitfähigkeiten der Mischkörper aus isotropen Substanzen. Ann. Phys. 1935, 416, 636-664. [CrossRef]

44. Vajjha, R.S.; Das, D.K. Experimental determination of thermal conductivity of three nanofluids and development of new correlations. Int. J. Heat Mass Transf. 2009, 52, 4675-4682. [CrossRef]

45. Buongiorno, J.; Venerus, D.C.; Prabhat, N.; McKrell, T.; Townsend, J.; Christianson, R.; Tolmachev, Y.V.; Keblinski, P.; Hu, L.; Alvarado, J.L.; et al. A benchmark study on the thermal conductivity of nanofluids. J. Appl. Phys. 2009, 106, 094312. [CrossRef]

46. Wang, X.Q.; Mujumdar, A.S. Heat transfer characteristics of nanofluids: A review. Int. J. Therm. Sci. 2007, 46, 1-19. [CrossRef]

47. Mahian, O.; Kianifar, A.; Kleinstreuer, C.; Al-Nimr, M.A.; Pop, I.; Sahin, A.Z.; Wongwises, S. A review of entropy generation in nanofluid flow. Int. J. Heat Mass Transf. 2013, 65, 514-532. [CrossRef]

48. Fluent Inc. Fluent 14.0 Theory Guide; Fluent Inc.: Pittsburgh, PA, USA, 2012.

49. Kock, F.; Herwig, H. Local entropy production in turbulent shear flows: A high-Reynolds number model with wall functions. Int. J. Heat Mass Transf. 2004, 47, 2205-2215. [CrossRef]

50. Cengel, Y.A.; Ghajar, A.J.; Ma, H. Heat and Mass Transfer: Fundamentals \& Applications, 4th ed.; McGraw-Hill: New York, NY, USA, 2011.

51. Bejan, A. Entropy Generation Minimization: The Method of Thermodynamic Optimization of Finite-Size Systems and Finite-Time Processes; CRC Press: Boca Raton, FL, USA, 1995.

(C) 2017 by the authors. Licensee MDPI, Basel, Switzerland. This article is an open access article distributed under the terms and conditions of the Creative Commons Attribution (CC BY) license (http:/ / creativecommons.org/licenses/by/4.0/). 